\title{
NO MATE A SU HIJO NI TORTURE A SU VECINO Sobre la obediencia y la irritante actualidad de los experimentos Milgram
}

\author{
RICARDO LÓPEZ ${ }^{(1)}$
}

"Quizás nuestra cultura no provee adecuados modelos de desobediencia".

Stanley Milgram

\section{EL VALOR DE LA OBEDIENCIA}

En forma simple, la obediencia es un tipo de comportamiento que se realiza con el objeto de responder a órdenes directas de una autoridad. Esto es, hay obediencia cuando una persona modifica su comportamiento para ajustarlo a una demanda proveniente de una fuente dotada de algún poder. Así, aunque parezca innecesario enfatizarlo, la obediencia necesariamente se vive al interior de una relación asimétrica. En el acto de obedecer una persona hace lo que otra quiere que haga, de modo que una cierta forma de predominio, subordinación o elemento jerárquico siempre está presente.

La conducta obediente puede ocurrir en circunstancias que una de las partes sea sometida por la fuerza. Por ejemplo, mediante amenaza, alguien más poderoso puede conseguir una respuesta conforme a su interés. En estos casos hablamos de coacción, porque el sometimiento ocurre por obra de la anticipación de un peligro. En este último caso se trata de situaciones fácilmente explicables, pero hay una variedad de conductas obedientes que no implican una coacción manifiesta, o están en una frontera en que la coacción es incierta.

Partamos de una obvia constatación. La obediencia es una conducta habitual en la ex-

periencia humana: los hijos obedecen a sus padres, los estudiantes obedecen a sus profesores, los empleados obedecen a sus jefes, los soldados obedecen a sus oficiales... y así a lo largo y ancho de la vida social. Con todos los matices posibles, y en grados variables de intensidad y arbitrariedad, la conducta obediente es parte de nuestras rutinas cotidianas.

Hasta aquí no hay mayores problemas. No hay comunidad que pueda vivir sin normas $y$ éstas de una u otra manera reclaman obediencia. No hay sociedad que carezca de autoridades, y éstas a su vez inevitablemente reclaman lo suyo. Pero hay excesos, y son muchos los casos en que la obediencia se ubica en un límite peligroso para la dignidad, la convivencia, la vida misma; y hasta para la imagen que tenemos de nosotros mismos.

Rudolf Hess ponía la obediencia por encima de todo, incluso de la lógica y la moral: "Tenga la seguridad que no era siempre muy placentero ver esas montañas de cadáveres y respirar ese continuo olor a quemado. Pero Himmler lo había ordenado, y yo jamás me detuve a pensar si era justo o injusto". Como él, muchos otros criminales de guerra, pronunciaron en los juicios de Nuremberg la más sencilla de las explicaciones: “... obedecía ordenes”a. Un ejemplo de una larga tradición de enseñanza de la obediencia.

Cosa parecida ocurrió con Rudolf Eichmann, quien en su defensa ante el tribunal que lo juzgó en Jerusalén, declaró que lo único que hizo fue cumplir su juramento nacionalsocia-

\footnotetext{
(1) Departamento de Educación en Ciencias de la Salud (Decsa). Facultad de Medicina. Universidad de Chile. rlopezp@med.uchile.cl

(a) William L. Shirer (1962). Auge y Caída del Tercer Reich. Barcelona. Luis de Caralt.
} 
lista que lo obligaba a ejecutar las órdenes sin discutir. Este personaje, que a lo largo de su vida nunca se apartó de la iglesia, según propia confesión, había hecho suya la intencionada versión del imperativo categórico de Kant, que circulaba en su círculo personal: "Obrad de tal manera que Führer, si tuviera conocimiento de vuestros actos, los aprobara"b.

Sería tranquilizador pensar que los excesos de la obediencia se limitan sólo al mundo militar. No es así. Muchos escuchamos desde niños esa historia en que Abraham es conminado a sacrificar a su hijo. No se trataba de una orden cualquiera, venía de lo alto. Debía llevar a su único hijo a la lejana tierra de Moria y ofrecerlo allí en holocausto. Estando todo preparado, el altar dispuesto y el niño atado, "alargó Abraham la mano y tomó el cuchillo para inmolar a su hijo" (Génesis, 22, 9). El sacrificio finalmente no ocurrió. Una voz, también desde alto, lo suspende todo, porque lo principal estaba demostrado. Abraham nunca recibe justificación alguna, ni siquiera la pide, arrastra a su hijo con engaños. Es un sujeto obediente y temeroso de la autoridad, ya no quedan dudas.

Relatada en un ambiente reflexivo, esta historia podría servir para pensar sobre el claroscuro de la obediencia, sus límites y sus excesos. Infortunadamente esto no se produce, al menos no es lo habitual. Muchas veces la obediencia se consagra en el orden social como un valor sin más.

\section{LA OBEDIENCIA EN EL LABORATORIO}

Stanley Milgram es un psicólogo social, que realizó desde los '60 una serie de experimentos sobre obediencia a la autoridad, cuyo impacto aún resuena en distintos ambientes. En sus primeras versiones, éstos se realizaron en la Universidad de Yale, y posteriormente, se repitieron y ampliaron en Princeton, y en otros lugares fuera de los Estados Unidos ${ }^{\mathrm{c}}$.

Consistían en pedir a un sujeto que aplica- se descargas eléctricas a otro, bajo pretexto de un propósito científico. El sujeto experimental disponía de un generador de descargas simulado, que tenía 30 interruptores graduados desde 15 hasta 450 voltios. En el comienzo de la línea ascendente de las descargas se podía leer "Descarga Leve", y al final "Descarga Grave". En síntesis, los distintos sujetos experimentales eran convocados al laboratorio para participar en una investigación supuestamente relativa al efecto del castigo sobre el aprendizaje. El sujeto actuaba como una especie de profesor que hacía preguntas que un participante debía responder. Todo estaba arreglado para que éste respondiera en forma equivocada, lo que provocaba de inmediato un castigo en forma de una descarga eléctrica. Ciertamente, el participante es un actor que no sufre dolor, pero el sujeto experimental no lo sabe, de modo que vive la situación como si fuese real.

Milgram realizó diecinueve versiones del experimento en las cuales participaron un total de 636 sujetos experimentales de edades entre 20 y 50 años, con un $40 \%$ de obreros, un $40 \%$ de empleados, y un $20 \%$ de profesionales. De este número, 265 alcanzaron la descarga máxima. Esto es, un equivalente del $42 \%$ obedeció al experimentador hasta el final, aplicando a una persona, desconocida hasta ese momento, una descarga de 450 voltios.

La escena experimental, enfrentaba al sujeto con sucesivas órdenes que le exigían aplicar descargas eléctricas crecientes, a una "víctima" que ubicada en una pieza vecina conectada a unos electrodos. En la mayor parte de los experimentos el sujeto sólo escucha a la "víctima", pero hay algunas variantes en que podía verla y tocarla. Cuando los sujetos expresan intenciones de abandonar el experimento, el experimentador los presiona. Cada manifestación de desobediencia provoca sucesivas exhortaciones para continuar, hasta en cuatro oportunidades. Cuando el sujeto se niega a aceptar la última demanda, ya no es presiona-

\footnotetext{
(b) Michel Onfray (2009). El Sueño de Eichmann. Pág. 25. Barcelona. Gedisa.

(c) Stanley Milgram (1974). Obedience to Authority. Harper \& Row.
} 
do y puede abandonar la escena. En este caso Milgram habla de conducta desobediente.

Dentro del 42\% global de obediencia, medido sobre la base de sujetos que han llegado a aplicar una descarga eventualmente mortal, existen algunas diferencias. En cuatro experimentos, el índice de obediencia alcanza los valores más altos, comprometiendo en uno de ellos a 37 sujetos de un total de 40. Estos experimentos fueron hechos en la universidad, y los experimentadores se presentaron con bata blanca y otros signos de autoridad científica.

Milgram interpreta que los sujetos no sienten ninguna responsabilidad personal por su acción, debido a que han recibido órdenes de una fuente con credibilidad científica. Subjetivamente los sujetos renuncian a su conciencia y se auto eximen de todo compromiso con su propia conducta. Al manipular la variable credibilidad, utilizando un experimentador de apariencia menos formal o llevando el experimento fuera de la universidad, la obediencia disminuye.

En el otro extremo, hay varios experimentos en que se observa una obediencia menor. En el experimento $\mathrm{N}^{\mathrm{o}} 17$, por ejemplo, la desobediencia aparece con fuerza. En este caso se dispone tres sujetos experimentales, dos de los cuales son cómplices que rápidamente se retiran de la escena desoyendo las órdenes. Milgram interpreta que al proporcionar unos modelos de desobediencia, los sujetos se inclinan con mayor facilidad a expresar su disconformidad y actuar en consecuencia.

\section{LA OBEDIENCIA Y LA CONCIENCIA}

Los experimentos Milgram no se prestan para simplificaciones. Hay quienes han creído ver en ellos una prueba de la maldad o el carácter fundamentalmente perverso de la naturaleza humana, en la medida que descubre la presencia emboscada de torturadores en potencia tras una fachada inocente. Eso es desproporcionado, Milgram ofrece un conjunto de ele- mentos para pensar sobre las condiciones que favorecen la obediencia, incluso sus excesos; pero en ningún caso llega a conclusiones definitivas ni hace generalizaciones tan amplias.

Los índices de obediencia son llamativos, pero no son absolutos y tienen variaciones que demuestran la participación específica de factores determinados para distintos casos. Los sujetos poseen disposiciones y formas de pensar sobre la autoridad y la agresión, pero -al mismo tiempo- se encuentran en una estructura social que compromete variables situacionales que actúan para desatar o frenar la obediencia. Las órdenes que exigen actuar contra otros, empujan a los sujetos a un punto de ruptura, a fin de forzar la desobediencia, pero en muchos casos ésta no llega. Los sujetos movilizan inhibiciones contra la desobediencia, poniendo a la vista una gran falta de recursos para resistir a la autoridad.

El ajuste más común del sujeto obediente consiste en verse a sí mismo como alguien que no es responsable de lo que pasa, porque es agente de una autoridad externa y legítima. En las entrevistas posexperimentales muchos sujetos expresan que continuaron su participación porque así se pidió. Esta es, probablemente, la lección más fundamental del estudio de Milgram: gente común sin disposiciones particulares hacia la hostilidad, ni rasgos patológicos, bajo ciertas condiciones llegan a ser protagonistas activos de la agresión.

Como buen psicólogo social, Milgram renuncia a un enfoque esencialista y prefiere un enfoque situacional: no se trata de la clase de seres humanos que somos, sino de la clase de situaciones en que nos encontramos. Los sujetos experimentales se orientaron de preferencia hacia las necesidades del experimentador, de la autoridad en suma, y no de la eventual "víctima". En muchos casos los sujetos fueron incapaces de expresar su molestia o disconformidad: "Muchos sujetos no pueden hallar la fórmula verbal específica que les permita rechazar el papel que les ha signado el expe-

(d) Stanley Milgram (1972). Condiciones de obediencia y desobediencia a la autoridad. Pág. 31. Incluido en Psicología Social 9. Ricardo Zúñiga, Editor. Valparaíso. UCV. 
rimentador. Quizás nuestra cultura no provee modelos adecuados de desobediencia"d.

\section{LA TORTURA Y EL PODER}

Para que alguien pueda mandar, alguien debe obedecer. Las relaciones de obediencia, como otras, no liberan a ninguna de las partes. Es posible, por tanto, acercarse a la comprensión de algunos excesos de la obediencia, sin recurrir a la cómoda explicación de un supuesto trastorno mental. En el marco de estos excesos existe la tortura. Una abrumadora evidencia indica que la tortura ha llegado a ser un fenómeno generalizado, una práctica habitual en numerosos Estados del mundo. No hablamos entonces de hechos distantes: lo sabemos en Chile.

Esto no ocurre sólo hoy, es un fenómeno que cruza el tiempo. No son excesos aislados o brotes pasajeros. Existe una continuidad histórica de la tortura amparada en muchas culturas, ideologías y formas de poder político. El camino hasta las refinadas prácticas actuales es largo y comienza tempranamente, cubre períodos en que su uso estuvo regulado y protegido por la tradición y las leyes; y aún otros en los que gozó del amparo divino.

La tortura es un crimen político. Incluye todas las prácticas recurrentes mediante las cuales se infiere daño y sufrimiento físico o psicológico a una persona, independientemente que concluya con su muerte. Es un hecho en el universo de la política, pero no como una relación de persona a persona, porque aún cuando ésta se produzca de hecho, ella existe al amparo de organizaciones generalmente oficiales y públicas. La tortura es una acción del poder contra el ciudadano, pertenezca o no a un grupo.

La tortura constituye una práctica del ejercicio del poder, una técnica de aplastamiento de la oposición política. Es el intento de conseguir mediante el dolor una respuesta de alguien que se resiste a darla. El objetivo central de la tortura es siempre la intimidación, y busca pa- ralizar la iniciativa de participación política. Es un recurso del poder destinado a modelar dentro del aprecio por el orden y la obediencia. La tortura somete, reemplaza la crítica por el conformismo. Modela de cierta manera que interesa al poder. Es una forma de pedagogía, pero en una versión singular: es una "pedagogía del terror". La tortura no se asocia únicamente con la destrucción. Hay destrucción, es cierto, pero sólo con vistas a construir de nuevo y $\sin$ error ${ }^{\mathrm{e}}$.

La tortura busca generar la obediencia, pero a su vez se explica por la obediencia. Es un fenómeno político al interior de relaciones formalizadas y jerarquizadas, en donde existe una víctima ya subvalorada, un contexto de impunidad, un ejecutor que recibe órdenes y alguien que las emite generalmente inspirado por un afán de higiene social.

En un espacio social en donde la obediencia llega ser un valor absoluto, y en donde existe una extendida, y correlativa, incapacidad para mantener la identidad frente a la autoridad, no es curioso que se desemboque en excesos como los que muestra Milgram, o los padecidos por los compatriotas incluidos en el Informe Valech. Mientras no se desarrolle una conciencia acentuada sobre los límites de la obediencia, suficiente como para discriminar en cada caso lo legítimo de lo ilegítimo; y consecuentemente una percepción sobre el sentido profundamente ético que puede tener la desobediencia, seguiremos lamentando excesos.

Nada de esto carece de complejidad ni de riesgos. La desobediencia de Antígona, legítima bajo todo punto de vista, desata un conflicto insalvable con la autoridad que sólo se cierra con su muerte.f Pero eso no es todo. Semejante grado de conciencia presupone personas de clara formación ética, con capacidad, ante todo, para pensar en forma autónoma y desarrollar argumentadamente sus posiciones. Presupone, desde luego, una confianza a toda prueba en el potencial de la palabra como el mejor de los recursos del poder.

\footnotetext{
(e) Edison Otero y Ricardo López (1989). Pedagogía del terror. Un ensayo sobre la tortura. Santiago. Atena.

(f) Sófocles (2002). Antígona. Santiago. Universitaria.
} 